\title{
O USO DE METODOLOGIAS ATIVAS DE ENSINO E APRENDIZAGEM: PERCEPÇÃO DOS DOCENTES DE CURSO DE FISIOTERAPIA
}

\section{USING ACTIVE LEARNING STRATEGIES: PERCEPTION OF COLLEGE PROFESSORS OF A PHYSIOTERAPY COURSE}

Alana Tâmisa Leonel (ORCID: 0000-0003-3293-8004)

Luiz Alfredo Braun Ferreira (ORCID: 0000-0002-7216-5619)

Rosiane Guetter Mello (ORCID: 0000-0002-0612-3955) ${ }^{2}$

Christian Boller(ORCID: 0000-0002-1777-6695)2

Autor Correspondente

Christian Boller

E-mail: christian.boller@gmail.com

\section{RESUMO}

As metodologias ativas de ensino e aprendizagem têm ganhado destaque no cenário do ensino superior nos últimos anos. Elas estão baseadas na premissa de que o estudante é o centro do processo educativo, e, para seu sucesso, há a necessidade do preparo técnico do docente. Muitos docentes do Curso de Fisioterapia, assim como de outras áreas da saúde, não receberam a capacitação necessária para trabalhar com essas metodologias ao longo dos seus anos de estudo na graduação ou mesmo em cursos de pós-graduação. Nesse aspecto, é grande a responsabilidade das Instituições de Ensino Superior em preparar esses docentes para atender à nova demanda do mercado educacional. Esta pesquisa teve como objetivo conhecer a percepção de docentes de um Curso de Fisioterapia do interior do Paraná em relação ao uso de metodologias ativas de ensino e aprendizagem. Caracteriza-se por um estudo de natureza qualitativa e de cunho exploratório e descritivo. A técnica escolhida para abordagem dos docentes foi o grupo focal, cujos encontros permitiram com que seis professores pudessem descrever a sua relação profissional com o uso das metodologias ativas de ensino. Os discursos foram categorizados pelo software MAXQDA, e seu conteúdo, analisado pelo referencial teórico de Bardin. Os resultados apontaram que os docentes se sentem inseguros quanto ao uso das metodologias ativas de ensino, justificado, em parte, pela falta de acesso a informações sobre o assunto e pela pouca oportunidade de praticar as diferentes técnicas em ambiente protegido fora do contexto da sala de aula.

Palavras-chave: Instituições de Ensino Superior; Fisioterapia; Ensino; Metodologia; Pesquisa Qualitativa.
${ }^{1}$ Curso de Fisioterapia. Faculdade Guairacá

${ }^{2}$ Pós-Graduação no Ensino nas Ciências da Saúde. Faculdades Pequeno Príncipe

a) Este trabalho é fruto da dissertação de mestrado de Alana Tâmisa Leonel, intitulado: "A percepção de docentes de um curso de fisioterapia sobre o uso de metodologias ativas de ensino e aprendizagem. 2019. Faculdades Pequeno Príncipe".

\begin{abstract}
Active teaching and learning methodologies have gained prominence in the higher education scenario in recent years. They are based on the premise that the student is the center of the educational process, and, for its success, there is a need for the teacher's technical preparation. Many professors from the Physiotherapy Course, as well as from other fields of health, did not receive the necessary training to work with these methodologies during their years of study at undergraduate level or even in Postgraduate courses. In this respect, there is a great responsibility of Higher Education Institutions in preparing these professionals to meet the new demand of the educational market. This research aimed to know the perception of professors of a Physical Therapy Course in the countryside of Paraná in relation to the use of active teaching and learning methodologies. It is characterized by a qualitative and exploratory and descriptive study. The technique chosen to approach the professors was the focus group, whose meetings allowed six teachers to describe their professional relationship with the use of active teaching methodologies. The speeches were categorized by the MAXQDA software and their content analyzed by Bardin's theoretical framework. The results showed that professors feel insecure about the use of active teaching methodologies, justified, in part by the lack of access to information on the subject and the little opportunity to practice different techniques in a protected environment outside the context of the classroom.
\end{abstract}




\section{INTRODUÇÃO}

Durante os anos iniciais da vida estudantil, desde o ensino infantil até o ensino médio, o estudante depara-se com uma série de informações e contextos que organizam seu comportamento. O ponto de ruptura desse processo é a passagem da adolescência para a vida adulta que, no universo acadêmico, ocorre na Universidade. Segundo as teorias de David Ausubel (1918 - 2008), o estudante precisa construir sua rede de conhecimentos do seu aspecto geral ao específico e que esta rede tenha significado próprio do estudante. Por outro lado, Carl Rogers (1902 - 1987) defende que essa rede de conhecimentos não deve ser forçada ao estudante, ele deve descobrir por si mesmo e transformar-se a partir do conhecimento adquirido ${ }^{1}$. Essa forma de pensar o ensino é reiterada no conceito de andragogia, no qual existe o acúmulo de experiências, aprendizagem pelos acertos e erros e percepção da falta de conhecimento. Assim, o indivíduo adulto é capaz de tomar para si uma informação e avaliar sua utilidade conforme suas necessidades ${ }^{2}$.

Essa forma de abordagem educacional é contrária àquela adotada na maioria das Instituições de Ensino Superior (IES), ou está começando a ser adotada em alguns nichos específicos, como é o caso dos Cursos da área da Saúde. Conhecida como metodologia tradicional de ensino, o foco principal do processo de ensino é o conteúdo; e, a partir dele, constroem-se disciplinas e matrizes curriculares. Essas ações são normalmente pensadas para grandes grupos nos quais se favorece a quantidade de informação no menor tempo possível, ou seja, o estudante é receptor (depositário) de assuntos relativos a um determinado tema ${ }^{3}$, sem a real necessidade de um pensamento lógico, crítico e reflexivo preconizado pela aprendizagem significativa ${ }^{4}$.

Como destacado, nos Cursos da área de Saúde, vêm-se adotando práticas de ensino que elegem a aprendizagem significativa e centrada no estudante. Elas objetivam a formação e a capacitação de profissionais mais humanos, éticos e políticos, instrumentados no princípio do cuidado. A organização curricular nessas IES tem por objetivo: 1) integrar a teoria com a prática; 2) integrar ensino e serviço em saúde; 3 ) promover a reflexão crítica sobre problemas e contextos reais do dia a dia profissional. Essa forma de ensino é classificada como Metodologia Ativa de Ensino e Aprendizagem (MAE), e possibilita ao estudante transformar-se em protagonista e corresponsável pela sua trajetória profissional, tirando do professor o papel centralizador do ensino e destacando sua atuação como incentivador e facilitador do processo de aprendizagem ${ }^{5}$.

A partir do exposto, percebe-se que as exigências do universo acadêmico requerem estudantes proativos no processo de ensino e aprendizagem e docentes preparados para romper paradigmas educacionais vigentes. Nesse quesito, enfrenta-se um problema quanto à formação docente: para a maioria dos cursos universitários brasileiros, a única exigência legal é possuir um diploma de bacharel. Além disso, nos casos específicos em que se exigem cursos de mestrado e doutorado, percebe-se que os programas de pós-graduação apresentam pouca ou nenhuma disciplina voltada à formação docente ${ }^{6}$. No caso específico dos Cursos de Fisioterapia, as Diretrizes Curriculares Nacionais enfatizam a formação de profissional apto ao trabalho em equipe e que analise estratégias, crie soluções possíveis dentro de cada conceito de saúde, paciente e família, que entre outros conceitos ligados à saúde coletiva não enfatizam a formação para a docência ${ }^{7}$.

Essa ausência de formação didático-pedagógica para professores universitários em cursos de bacharelado tem causado problemas no processo de ensino e aprendizagem ${ }^{6}$, em especial em uma época em que o acesso rápido e facilitado a informações por meio de internet faz com que os estudantes não aceitem mais a informação livresca e que pode, em muitos casos, estar desatualizada. A sociedade (e os estudantes) do século XXI exige que 
o processo de ensino seja tão dinâmico quanto as informações recebidas por meios não acadêmicos ${ }^{8}$.

Seguindo a linha de pensamento destacada nesta introdução, o objetivo deste trabalho foi compreender como docentes do Curso de Fisioterapia de uma IES do interior do estado do Paraná percebem a implantação e o uso de MAE nas diferentes disciplinas do curso.

\section{MÉTODOS}

A presente pesquisa, de abordagem qualitativa e de cunho exploratório e descritivo, tem por interesse estudar a percepção dos professores do Curso de Fisioterapia de IES do interior do estado do Paraná. Por percepção, entende-se um processo pelo qual o indivíduo seleciona, organiza e interpreta os diferentes estímulos recebidos do meio; e, após, traduz em uma imagem (ou linguagem) própria, coerente e significativa ${ }^{9}$. Assim, não é possível aos pesquisadores determinarem com exatidão, a percepção de um grupo, uma vez que ela é individual de cada sujeito e traz consigo toda uma bagagem cultural e social.

Para sobrepor essa dificuldade, optou-se por não utilizar questionários pré-formatados, uma vez que estes induzem a um conceito formado do próprio pesquisador. Assim, a técnica utilizada neste estudo foi a do grupo focal, pois ela permite a compreensão da realidade vivenciada por grupos predeterminados assim como suas atitudes e comportamentos mais relevantes em relação ao fato pesquisado ${ }^{10}$. Além disso, a técnica tem por objetivo assegurar o entendimento do fenômeno em profundidade e sem a generalização dos resultados ${ }^{11}$.

Para efetivação desta pesquisa, os docentes de Curso de Fisioterapia de IES do interior do estado do Paraná, com, no mínimo, um ano de experiência docente, foram convidados por meio de amostragem não probabilística e intencional. A amostra do estudo foi composta por seis professores que foram entrevistados conforme a técnica de grupo focal - que não é uma técnica de entrevista entre sujeito e pesquisador, visto que ela envolve a conversa dos participantes cujo contexto é delineado previamente pelo pesquisador por meio de perguntas disparadoras. Essa forma de abordagem permite a livre circulação de ideias entre os participantes com o mínimo de interferência do pesquisador ${ }^{12}$.

A sessão de grupo focal teve duração de 1 hora e 45 minutos e teve como temas disparadores os seguintes tópicos (e subtópicos): 1) Papel do professor no ensino superior (qual é o papel; se é detentor, facilitador, tutor ou influenciador do conhecimento); 2) Plano de aula (o que é; por que usar; quando usar; como usar; como você realiza); 3) Metodologia tradicional de ensino (idem ao 2); 4) Metodologia ativa de ensino (idem ao 2; qual sua percepção/visão em relação ao uso de MAE; quais os benefícios do uso das MAE; quais as dificuldades em relação ao uso das MAE); 5) Você utiliza MAE (quais; como; com quais turmas; recebeu formação; como se sente ao utilizar).

Para efeitos de registro, as discussões do grupo focal foram gravadas e, após, transcritas em texto. Para análise das informações, foi utilizado o referencial teórico de análise de conteúdo ${ }^{13}$. Essa técnica envolve a leitura flutuante do discurso seguida pela organização das ideias em grupos ou categorias, criadas a posteriori. Essas categorias surgem quando os recortes dos discursos dos participantes são agrupados por possuírem características próximas; assim os elementos de significação existentes nas mensagens são organizados conforme a frequência (ou ausência) de itens que dão sentido à fala. Para essa etapa, foi utilizado o software MAXQDA que permite organizar com facilidade os discursos dentro de cada categoria elencada pelo pesquisador.

Esta pesquisa foi submetida à apreciação do Comitê de Ética em Pesquisa e foi aprovada sob número 2.959.904. Todos os participantes que aceitaram participar do trabalho assinaram Termo de Consentimento Livre e Esclarecido, e suas identidades estão preservadas pelo uso de códigos (P1-6).

\section{RESULTADOS E DISCUSSÃO}

A pergunta disparadora inicial do grupo focal envolveu perguntas sociodemográficas, que, além de contribuir com a pesquisa, permitem que os sujeitos participantes fiquem mais à vontade com o 


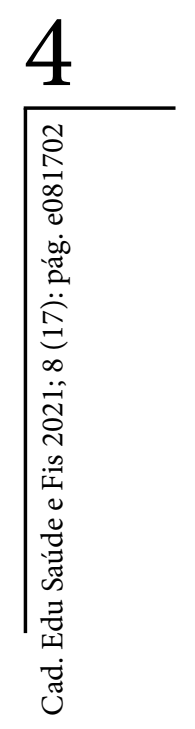

processo. Essa etapa é importante, pois tira a atenção dos sujeitos da pesquisa sobre o pesquisador e cria um clima de intimidade entre os sujeitos, que permite uma interação mais harmônica ${ }^{12}$.

O quadro 1 apresenta os dados sociodemográficos dos participantes da pesquisa. Eles foram ordenados em relação a gênero, idade, formação acadêmica, tempo de docência, tipo de instituição que já atuou como docente e se possui alguma formação em docência.

Quadro 1. Perfil dos participantes

\begin{tabular}{|c|c|c|c|c|c|}
\hline Participante & Idade & Formação & $\begin{array}{l}\text { Tempo de } \\
\text { docência }\end{array}$ & $\begin{array}{l}\text { Instituição em } \\
\text { que atuou }\end{array}$ & $\begin{array}{l}\text { Formação em } \\
\text { docência }\end{array}$ \\
\hline P1 - Feminino & 36 & Mestrado & 8 anos & $\begin{array}{ll}\text { Privada } & \mathrm{e} \\
\text { Estadual } & \\
\text { (técnico) } & \end{array}$ & $\begin{array}{l}\text { MBA e semana } \\
\text { pedagógica } \\
\text { oferecidos pela } \\
\text { IES }\end{array}$ \\
\hline P2 - Feminino & 38 & Mestrado & 6 anos & Privada & $\begin{array}{l}\text { MBA e semana } \\
\text { pedagógica } \\
\text { oferecidos pela } \\
\text { IES }\end{array}$ \\
\hline P3 - Masculino & 32 & Especialização & 4 anos & $\begin{array}{l}\text { Privada } \\
\text { (graduação e } \\
\text { técnico) }\end{array}$ & $\begin{array}{l}\text { MBA e semana } \\
\text { pedagógica } \\
\text { oferecidos pela } \\
\text { IES }\end{array}$ \\
\hline P4 - Feminino & 28 & Mestrado & 3 anos & $\begin{array}{ll}\text { Privada } & \mathrm{e} \\
\text { Estadual } & \end{array}$ & $\begin{array}{l}\text { MBA e semana } \\
\text { pedagógica } \\
\text { oferecidos pela } \\
\text { IES }\end{array}$ \\
\hline P5 - Masculino & 33 & Doutorado & 10 anos & $\begin{array}{l}\text { Privada } \quad \mathrm{e} \\
\text { Estadual }\end{array}$ & $\begin{array}{l}\text { MBA e semana } \\
\text { pedagógica } \\
\text { oferecidos pela } \\
\text { IES }\end{array}$ \\
\hline P6 - Feminino & 48 & Mestrado & 16 anos & $\begin{array}{ll}\text { Privada } & \mathrm{e} \\
\text { Estadual } & \end{array}$ & $\begin{array}{l}\text { MBA e semana } \\
\text { pedagógica } \\
\text { oferecidos pela } \\
\text { IES }\end{array}$ \\
\hline
\end{tabular}

Fonte: elaboração própria, 2019. 
Devido à dificuldade técnica em promover o encontro dos seis docentes no mesmo dia e horário, foi necessário dividir a coleta de dados em dois dias - em cada, dia participaram três docentes para a realização do grupo focal. A tarefa de reunir pessoas para um grupo focal não é fácil e pode acontecer por vários motivos, como desconfiança entre os participantes, dificuldade de reuniões coletivas, limitações comunicativas e insegurança em relação ao anonimato e confidencialidade dos dados por envolver muitas pessoas ${ }^{14}$. Essas características podem ser minimizadas; e é inclusive estimulado que os participantes sejam escolhidos por ordem de proximidade social, desde que não exista relação hierárquica entre eles ${ }^{12}$.

Apesar de a amostra ser considerada pequena, ela mostrou-se eficaz para esta pesquisa, pela quantidade de conteúdo e riqueza de dados levantados, evidenciando o perfil dos participantes e a sua relação com o tema em estudo, uma vez que todos são profissionais com experiência na docência. Descritivamente, a amostra é caracterizada como essencialmente do gênero feminino $(66,6 \%)$; com mestrado $(66,6 \%)$, com média de $7,8 \pm 4,8$ anos de tempo de docência, e todos já receberam cursos de formação em metodologias ativas no período de semana de formação acadêmica.

Além da observação da riqueza de informação prestada, o número de participantes está de acordo com a literatura. Sugere-se que, para que o grupo possa desenvolver com fluência as discussões de modo que os resultados possam ser significantes, o número mínimo de participantes é de quatro. Também não é interessante que o número de participantes seja superior a 15, uma vez que podem surgir conversas paralelas com maior frequência, sem que isso tenha conexão com o trabalho a ser desenvolvido ${ }^{15}$. Apesar da divergência entre valores, o fator principal é que todos os participantes tenham chance de participar, assim, considera-se que o resulto da pesquisa foi efetivo, uma vez que todos puderam participar e que está dentro dos valores destacados na literatura.

Após transcrição dos diálogos, desenvolveu-se a Análise de Conteúdo ${ }^{13}$. A análise das informações seguiu as fases propostas pelo autor: 1) Pré-análise, fase em que o material coletado é organizado, objetivando a sistematização das ideias; 2) Exploração do Material e Tratamento dos resultados representam a fase de estudo do material por meio da análise dos discursos e categorização/codificação das falas; 3) Interpretação dos resultados, nessa fase é realizada a interpretação intuitiva, reflexiva e crítica dos resultados.

Assim, as categorias apreendidas a partir dos discursos foram: "O papel do professor no ensino superior", "Utilização das MAE", e "MAE". Os termos utilizados para denominar as categorias possuem relação com os temas encontrados nas falas dos professores participantes do grupo focal, reunindo todas as suas impressões e experiências relacionadas com os grandes temas de categorização. O quadro 2 apresenta as descrições de cada categoria, obtidas a partir dos discursos.

Quadro 2 - Categorias de análise e suas descrições

\begin{tabular}{|c|c|}
\hline Categorias & Descrição \\
\hline $\begin{array}{l}\text { O papel do professor no ensino } \\
\text { superior }\end{array}$ & $\begin{array}{l}\text { Diz respeito ao entendimento do professor sobre a sua } \\
\text { função no ensino superior, como figura que representa } \\
\text { o indivíduo de maior titulação dentro da sala de aula. }\end{array}$ \\
\hline $\begin{array}{l}\text { Utilização das metodologias } \\
\text { ativas de ensino e aprendizagem }\end{array}$ & $\begin{array}{l}\text { Relacionada com a frequência com que o professor } \\
\text { utiliza as metodologias ativas de ensino e aprendizagem } \\
\text { em sala de aula, como as prepara e quais são as } \\
\text { maiores dificuldades e os maiores benefícios da } \\
\text { utilização. }\end{array}$ \\
\hline $\begin{array}{l}\text { Metodologia ativa de ensino e } \\
\text { aprendizagem }\end{array}$ & $\begin{array}{l}\text { Contempla o que se entende por metodologia ativa de } \\
\text { ensino e aprendizagem e discorre sobre as experiências } \\
\text { vivenciadas por cada professor, relacionada a utilização } \\
\text { e formação em metodologias ativas. }\end{array}$ \\
\hline
\end{tabular}


Tradicionalmente, as análises de discursos são realizadas de forma manual. Com o desenvolvimento da informática, softwares de análises numéricas expandiram no mercado, já softwares para análise textual são menos frequentes. Apesar de pouco utilizados, os softwares de análise de dados qualitativos, como o MAXQDA, são de grande valia para as pesquisas qualitativas, pois permitem reduzir o tempo de codificação e análise dos dados, possibilitando o relato de todas as etapas do processo de forma clara e transparente, além de melhorar os recursos de apresentação dos resultados ${ }^{16}$.

Assim, a codificação das categorias por meio do software MAXQDA resultou nos dados da tabela 1 .

Tabela 1. Categorias de análise e conjuntos de respostas

\begin{tabular}{llll}
\hline Categoria de análise & Respostas & Conjunto de respostas & Respostas \\
\hline $\begin{array}{l}\text { Papel do professor no } \\
\text { ensino superior }\end{array}$ & 27 & No ensino superior & 7 \\
& & $\begin{array}{l}\text { Características do professor } \\
\text { Detentor do conhecimento }\end{array}$ & 13 \\
\hline Utilização de & 42 & Formação em MAE & 5 \\
metodologia ativa de & MAE na instituição & 14 \\
ensino & e & Quais MAE já utilizaram & 9 \\
aprendizagem (MAE) & OSCE & 14 \\
\hline Metodologia ativa de & 52 & Dificuldades & 11 \\
ensino & e & Benefícios & 7 \\
aprendizagem & MAE em grupos & 9 \\
& Percepção do aluno e do professor & 5 \\
& Quando usar & 13 \\
\hline
\end{tabular}

Fonte: elaboração própria, 2019.

A partir dessa tabela, será considerada em separado cada uma das categorias apresentadas. 


\section{Papel do professor no ensino superior}

No primeiro momento de diálogo sobre o tema, observou-se um discurso muito claro dos professores em relação a sua função no ensino superior, em que as repostas foram semelhantes e enalteciam as características de exemplo e de facilitador, como pode-se observar nos discursos abaixo.

"Qual o papel do professor? Puxa vida. Eu acho, que é facilitar a forma de aprendizagem do aluno, (...) a gente é um mediador, um facilitador do aprendizado deles, acho que essa é a função do professor." (P5)

"Eu acho que dentro da profissão nossa, é muito mais que o papel de ensinar, a gente tem que ser um exemplo." (P2)

"Um facilitador, um exemplo pra que eles." (P1)

Esse discurso encontra ressonância na literatura ${ }^{17}$, na qual se afirma que o ensinar docente atual precisa de características diferentes das tradicionais, que os professores precisam ser reflexivos e críticos no ensino de suas disciplinas. Além desse, o docente precisa ser capacitado a promover uma transformação da sociedade acadêmica, seus valores e sua forma de trabalhar. Isso exige do professor uma habilidade para integrar saberes teóricos de sua área de atuação, políticos e pedagógicos para, assim, facilitar o processo de aprendizado de seus alunos.

Durante a conversa, os docentes foram questionados sobre algumas características do professor, como influenciador, tutor, detentor e facilitador. Nesse ponto, perceberam-se divergências de ideias sobre qual seria a melhor definição.

"Eu acho que o tutor também se aplica, e o facilitador também. Porque eu acho que um dos papéis do professor, é ele tentar passar o conhecimento dele pro o aluno, mas sem entregar pronto pra ele, sendo assim, um tutor, direcionando esse aluno, mas ele tem que fazer com que esse aluno busque o conhecimento." (P6)

"E nem tutor, né. Porque acho que a tutoria às vezes a gente presta, mas eu acho que ele tem que ser mais ativo. Porque quando a gente fica só na tutoria pra ele, eu acho que só dá, dá, entrega, e tutoria, e fala faça né. Mas, a gente vem de uma formação completamente detentor mesmo, eu sou autoridade, e eu vou passar pra você só o que eu sei, e o que eu tenho zona de conforto, agora se tem coisa diferente da área que eu ensino, você se vire aprender." (P1)

Analisando as falas dos professores, nota-se que há discordância sobre o conceito de tutoria, que faz pensar se eles conhecem o real sentindo e funcionamento de uma tutoria no ensino superior. Nesse sentido, a definição esperada dos docentes seria de que este é o profissional referência dos alunos, com a função de acompanhar o processo de aprendizagem, tanto científica quanto pessoal, auxiliando o aluno a conhecer suas maiores habilidades e fraquezas ${ }^{18}$.

Da mesma forma, observou-se que não houve uma descrição unânime em relação ao papel do professor no ensino superior. Esse tópico é apontado na literatura como uma das falhas da formação de bacharéis. O papel docente não é estimulado durante a graduação, salvo em poucos momentos em que estudantes participam de atividades como monitoria. Ao contrário, os estudantes são estimulados a participar de cursos de desenvolvimento profissional em detrimento da formação pedagógica $^{19}$.

\section{Metodologia Ativa de Ensino e Aprendizagem}

Os professores participantes do grupo focal foram formados em quase sua totalidade em metodologia tradicional de ensino, em que o professor chega à sala e, em forma de palestra, para grandes grupos, transmite todo o conteúdo e se despede. Não vivenciaram um ensino mais ativo, mais prático, e isso aparece nas discussões em grupo de forma explícita.

Quando foram questionados em relação ao que entendiam por metodologia tradicional de ensino, as respostas foram de acordo com a afirmação do primeiro participante.

"Pra mim, metodologia tradicional é quando você dá a aula de cabo a rabo, você chega falando e sai falando." (P6) 
"Eu concordo com o P6." (P5)

"Eu também, porque se a gente não dá essa aula falada, do começo ao fim, dá impressão que você não tá fazendo a tua parte, por completo, dá a impressão, ah não sei gente, eu sinto que parece que eu preciso falar, mas não precisa né!" (P4)

"Eu acho que é quando o professor fica lá na frente só falando e o aluno sentado o tempo todo só ouvindo.” (P3) nal." (P2)

"Isso é verdade, essa é a tradicio-

A noção de que a forma de ensino adotada pelas instituições se baseia na repetição de conteúdo e entende aluno como ser passivo não é nova ${ }^{3}$. Esse modelo, muito questionado nos modelos ativos de ensino, entende o professor como responsável por selecionar o material e entregá-lo pronto ao estudante, sem brechas para discussões de casos. Também tem como característica a divisão do currículo em disciplinas básicas e profissionalizantes, dedicando apenas os últimos anos para a formação prática do profissional.

Atualmente, fala-se muito em estimular o aprendizado por competências durante a graduação. Adota-se, aqui, a definição de que competência é a capacidade de identificar problemas e desafios, buscando soluções e tomando decisões no tempo adequado com base científica e embasado na prática. Assim, o aprendizado por competência deve prezar pelo desenvolvimento da autonomia do estudante, fato ignorado pelas metodologias tradicionais $^{20}$.

Essa visão é percebida pelos professores participantes da pesquisa. Eles destacam a necessidade de mudar as práticas educativas para atender ao novo perfil profissional exigido pela sociedade atual, mesmo que existam dúvidas sobre o assunto e que exijam rupturas da forma de pensar educação.

"Eu acho que a metodologia ativa, ela não pode ser única, eu acho que na nossa profissão, na nossa condição de fisioterapeuta, ela se aplica melhor em casos clínicos, em aplicação prática daquilo que foi dado na teórica, eu vejo melhor em outras profissões, como pedagogia por exemplo, ela tem um peso mas participativo, eu enxergo ela bem, mas na área da fisioterapia, eu acho que uma parte teórica precisa ser dada, pra poder entrar na metodologia ativa como resolução de caso, como discussão dos alunos para solucionar uma doença, eu acho que ela entra nesse aspecto aí." (P5)

"Que nem uma disciplina, fisiologia, por exemplo, já me falaram, nossa em fisiologia dá pra fazer muita coisa com metodologia ativa, eu não imagino o nosso aluno aprendendo tudo, todo o processo sozinho, por exemplo uma bomba de sódio e potássio e vir discutir comigo em sala sobre bomba de sódio e potássio, é, eu não sei eu não imagino a fisiologia, sendo aplicada inteiramente em metodologia ativa." (P4)

"Você pegue esse tradicional e você faça ela de uma maneira mais atrativa, mas, eu vejo, outro dia eu tava ouvindo falar, de anatomia que o pessoal não dá aula de anatomia, eu não imagino como anatomia não seja dada como anatomia, que você não pegue ali ó, tá vendo a foto aqui, mostrar exatamente origem e inserção muscular por exemplo." (P6)

E o P5 retoma a fala e complementa sua ideia inicial:

"Eu acho que tem algumas profissões que é muito difícil mesmo. Na nossa, a gente ainda tem essa vantagem tem como expor um caso clínico, de levar um paciente pra contar sua história, e os alunos em grupo planejarem o tratamento, eu acho que nessa parte mais prática mesmo, mas a teoria, tem coisa que você tem de partir de pré-conceitos." (P5)

A metodologia ativa é um processo de modificação da forma de ensinar, que deve ser focada na ação-reflexão-ação para se aproximar das indigências da atual política de saúde. A MAE acontece quando o processo de ensino puramente técnico deixa de existir e passa a instigar a formação reflexiva e humanística do aluno. 
Entretanto, para que esse processo aconteça, muitos desafios devem ser superados, principalmente os de questão estrutural, de organização pedagógica e administrativa das instituições, além da forma como estudantes e professores agem entre si e no que eles acreditam ${ }^{21}$.

\section{Utilização das MAE}

O último ponto a ser disparado para discussão dos participantes foi o conhecimento sobre as diferentes técnicas descritas como MAE. Observou-se nesse ponto que, embora haja compreensão da necessidade das metodologias ativas, os docentes conhecem pouco sobre os diferentes tipos de métodos de ensino que estão agrupados no contexto das MAE. Em parte, isso possa ser justificado pela formação docente. Como a maioria dos participantes declarou, sua formação em metodologias ativas está associada à semana de formação docente. Isso leva a pensar se, no processo de formação continuada, a IES aborda poucas metodologias, dando destaque apenas para aquelas que se adequam ao contexto do curso ou da instituição.

$$
\text { “ } O P B L "(\mathrm{P} 2)
$$

"Eu acho que o PBL, caso clínico né e o TBL." (P1)

"E aquele negócio de times lá, ah é o TBL." (P2)

"Eu uso caso clínico, o que eu consigo fazer é caso clínico com eles." (P3)

"Еu na verdade eu ainda tenho um pouco dificuldade com a metodologia ativa, eu acho que eu tô aprendendo, então por exemplo o que eu fiz outro dia, eu peguei o conteúdo que ia ser dado, eu dividi vários conteúdos pra eles, eles fizeram vídeos daquele conteúdo, e trouxeram e apresentaram o vídeo e eu me surpreendi, porque saíram ótimos vídeos. Uma outra coisa que eu nunca tinha feito, que pra mim isso seria o fim do mundo, prova em dupla, eu me surpreendi com uma prova em dupla, deu tanta discussão na sala, pra fazer a prova, que eu falei meu Deus, eles tão aprendendo mais, do que se eles estivessem fazendo a prova, eu fiquei muito surpresa, porque eu sou totalmente contra, na minha cabeça tradicional, era totalmente contra fazer prova em dupla, e eu me surpreendi meu Deus do céu eu nunca esperava isso." (P6)

"Eu ainda consigo uns $P B L$, uns $T B L$, eu já tô arriscando um pouco mais, caso clínico também sempre uso, na verdade nós já utilizávamos metodologia ativa, só a gente não sabia que chamava isso. Eu comecei fazer uma reflexão das minhas aulas, eu acho que a gente já trabalhava, não tão aperfeiçoado e com nome e com as formas." (P5)

"Uma maneira deles fixarem o conteúdo no final da aula, às vezes eu faço questões daquela aula, como que é, tem um nome pra isso, né?! Não sei... É tipo uma revisão... dai eles levantam as plaquinhas, sabe as plaquinhas lá!?" (P2)

E vocês conseguem realizar todos os passos da estruturação de um PBL ou de um TBL? (Pesquisadora)

"Eu não conheço os passos, monto um caso clínico, divido eles em grupos e peço para discutirem." (P3)

"Mas, vou falar pra você o dia que eu fiz o TBL, eu imprimi passo a passo e vim montando o checklist, eu vim tickando, fiz isso, fiz aquilo, porque eu falo fazer meia boca, falar que fez, beleza, mas o duro é falar que fez de forma correta. Eu achei, em um site, que é uns menininhos que fica falando, é bem explicativo, é bastante desenho e ele fala só de metodologia ativa e de lá eu tirei o checklist de como montar, primeiro passo faça isso, segundo passo faça aquilo, terceiro passo... Eu vi lá e depois montei o meu, aí na sala de aula eu vim checando o checklist." (P1)

Novamente, os discursos aproximam-se dos resultados encontrados por outros autores. Existe uma resistência dos docentes no uso de novos métodos de ensino em decorrência, principalmente, da falta de conhecimento sobre práticas pedagógicas. Para superar esse abismo, sugere-se o uso de técnicas de organização do aprendizado, uma vez que é necessário criar uma meta a ser alcança para, após, determinar como o caminho será percorrido. Estratégias de organização do plano de ensino como o Design Instrucional ${ }^{22}$ ou mesmo o Design Reverso ${ }^{23}$ tendem a 
auxiliar o docente na escolha da técnica adequada.

Nesse contexto, o trabalho docente no ensino superior ultrapassa as fronteiras da sala de aula. O que aos poucos se percebe, e deve se aprofundar com o aumento de estudos sobre a docência no ensino superior, é que o ato de ensinar deveria exigir do professor um aprendizado relacional. Por relação, entende-se que, além da capacitação técnica em métodos de ensino inovadores, o professor também deve deixar-se reger pelos estudantes. A tomada de decisão quando a concepção, a execução, a avaliação do processo didático são de responsabilidade do professore e, também, do estudante ${ }^{23}$. A sociedade moderna tem mostrado esses aspectos, e cabe ao meio acadêmico internalizar estas perspectivas, de que o conhecimento não tem dono, muito menos é unidirecional.

Com isso, vemos que, aos professores, faltam preparo e formação sobre MAE para facilitar a aplicação e desenvolvimento dessas técnicas em sala de aula.

\section{CONCLUSÕES}

As discussões acerca da docência no ensino superior estão iniciando seu fervor. Nos cursos da área da saúde, muito se tem debatido sobre a melhor forma de ensinar determinado conteúdo. A pesquisa aqui apresentada demostra como a realidade nacional também se apresenta em um microambiente universitário específico. A falta de compreensão da prática pedagógica por parte dos docentes associada à dificuldade de aproximar essa prática ao perfil dos estudantes do século XXI estão entre as questões que afetam a qualidade do processo ensino-aprendizagem em um Curso de Fisioterapia do Interior do Paraná.

Isso leva a pensar em outros estudos acerca do tema; em especial, como levar a esses docentes uma formação pedagógica específica e que atenda à demanda por um ensino de qualidade e alinhado às políticas educacionais vigentes. Estudos futuros neste e em ouros contexto mostrarão o caminho a ser trilhado - e, neste, as metodologias ativas de ensino terão seu espaço.

\section{REFERÊNCIAS}

1. Nogueira MOG, Leal D. Teorias da aprendizagem. 2. ed. Curitiba: Intersaberes; 2015.

2. Carvalho JA, Carvalho MP, Barreto MAM, Alves FA. Andragogia: Considerações sobre a aprendizagem do adulto. REMPEC - Ensino, Saúde e Ambiente. 2010;3(1):78-90.

3. Abreu JRP. Contexto atual do ensino médico: metodologias tradicionais e ativas - necessidades pedagógicas dos professores e da estrutura das escolas [dissertação]. Porto Alegre (RS): Universidade Federal do Rio Grade do Sul; 2009.

4. Cotta RMM, Silva LS, Lopes LL, Gomes $\mathrm{KO}$, Cotta FM, Lugarinho R, et al. Construção de portfólios coletivos em currículos tradicionais: uma proposta inovadora de ensino-aprendizagem. Ciênc Saúde Coletiva. 2012;17(3):787-796.

5. Rosa RS, Sanchez GJC, Gomes ICR, Silva MLM, Duarte ACS, Boery RNSO. Strategies Based on Active Methodologies in First Aid Teaching-Learning: Experience Report. J Nurs UFPE. 2017;11(2):798-803.

6. Barbosa ES, Ferreira MN, Nóbrega-Therrien SM. O ser professor e o seu desenvolvimento profissional na perspectiva de enfermeiros que lecionam no ensino superior. Revista COCAR. 2016;10(20):274-295.

7. Bombardelli CL, Siliano MR, Guerra ZF. Atualização das Diretrizes Curriculares Nacionais de Fisioterapia: avanço ou retrocesso? Revista Científica CIF Brasil. 2017;9(9):1-12.

8. Troncon LEA, Bollela VR, Borges MC, Rodrigues MLV. A formação e o desenvolvimento docente para cursos das profissões da saúde: muito mais que o domínio de conteúdos. Medicina (Ribeirão Preto). 2014;47(3):245-248.

9. Endo ACB, Roque MAB. Atenção, memória e percepção: uma análise conceitual da Neuropsicologia aplicada à propaganda e sua influência no comportamento do consumidor. Intercom - RBCC. 2017;40(1):77-96.

10. Lopes BEM. Grupo focal na pesquisa 
em ciências sociais e humanas. Revista Educação e Políticas em Debate. 2014;3(2):482-492.

11. Barros CMP, Dias AMI. A formação pedagógica de docentes bacharéis na educação superior: construindo o Estado da Questão. Revista Edu Questão. 2016;54(40):42-74.

12. Barbour R. Grupos focais. Porto Alegre: Artmed; 2009.

13. Bardin L. Análise de Conteúdo. São Paulo: Almedina; 2011.

14. Morgan DL. Focus groups as qualitative research. 2nd ed. London: Sage Publications; 1997.

15. Souza MKB, Lima YOR, Paz BMS, Costa EA, Cunha ABO, Santos R. Potencialidades da técnica de grupo focal para a pesquisa em vigilância sanitária e atenção primária à saúde. Rev Pesqui Qual. 2019;7(13):57-71

16. Nunes JV, Woloszyn M, Gonçalves BS, Pinto MDS. A pesquisa qualitativa apoiada por softwares de análise de dados: uma investigação a partir de exemplos. Revista fronteiras - estudos midiáticos. 2017;19(2):233-244.

17. Barbosa RLL, organizadora. Formação de educadores: desafios e perspectivas. São Paulo: Ed. UNESP; 2003.

18. Simão AMV, Flores A, Fernandes S, Figueira C. Tutoria no ensino superior: concepções e práticas. Sísifo: revista de ciências da educação. 2008; 7: 75-88.
19. Oliveira AD. A formação didático-pedagógica do professor do Ensino Superior egresso do bacharelado. Evidência. 2015;11(11):31-40.

20. Küller JA, Rodrigo NF. Metodologia de desenvolvimento de competências. São Paulo: Senac; 2017.

21. Mesquita SKC, Menezes RMV, Ramos DKR. Metodologias ativas de ensino/aprendizagem: dificuldades de docentes de um curso de enfermagem. Trab Educ Saúde. 2016;14(2):473-486.

22. Branch RM. Instructional design: the ADDIE approach. New York: Springer, 2009.

23. Wiggins G, Mctighe J. Understanding by design. 2nd ed. Alexandria, VA: ASCD; 2005.

24. Veiga IPA. A docência na Educação Superior e as didáticas especiais: campos em construção. Educação. 2011;36(3):455-464. 